\title{
LA ENSEÑANZA ELEMENTAL Y RABÍNICA \\ EN LA PALESTINA DE LOS PRIMEROS SIGLOS DE LA ERA CRISTIANA
}

Pedro P. Soto Canales*

\section{INTRODUCCIÓN}

Han pasado dos años desde que presentaba en la revista Riesgo de Educar ${ }^{1}$ mi artículo sobre la educación en el incanato, en donde al referirme a las actividades realizadas por el hombre en el Tahuantinsuyo, citaba al cronista Guamán Poma de Ayala, quien las describía y dividía teniendo como base la edad cronológica del individuo. Hago esta mención, pues recientemente he tenido la oportunidad de leer el trabajo de Ángel Ciriza Aguirre sobre el Pirke Avout (Mishná) en el contexto de la tradición de Israel. En este texto el autor también cita las diversas obligaciones y características que rodean al hombre judío piadoso según su edad. Así, se señala en el Pirke Avout 5,2 que:

A los cinco años se empieza a aprender la Torá; a los diez la Mishná; a los trece empieza la obligación de la observancia de los

* Es docente del Área de Historia de la Facultad de Ciencias de la Educación de la UCSS.

1 Revista de la Facultad de Ciencias de la Educación de la Universidad Católica Sedes Sapientiae, año 2, N.o 3, 2007. 
preceptos religiosos; a los quince se puede empezar el estudio del Talmud; a los dieciocho se está ya preparado para el matrimonio; a los veinte para procurarse el modo de vivir; a los treinta años se está en la edad del vigor; a los cuarenta en la edad de la sabiduría, a los cincuenta se puede dar consejos; a los sesenta años se entra a la vejez; a los setenta a las canas; a los ochenta años es la edad de la debilidad; a los noventa se camina encorvados; y al que llega a los cien hay que considerarlo ya muerto y fuera del mundo. (Ciriza 2004: 124)

A partir de esta semejanza entre ambas culturas, me propuse indagar sobre la educación entre los niños, jóvenes y adultos judíos, ya que, al revisar libros sobre historia de la educación, he observado que es muy significativa la lectura con respecto a este tema, debido a que se presenta muchas veces de manera genérica y poco comprensible. Inclusive yo mismo, al finalizar el presente artículo, he percibido que escribir sobre educación judía es ingresar a un vasto mundo de sabiduría, a veces muy difícil de comprender, de explicar y, por lo tanto, de trasmitir.

Por esta razón, mi estudio se limita inicialmente a la Palestina, para paulatinamente ir comprendiendo el desenvolvimiento de las comunidades que existían fuera de ella. Con respecto al tiempo cronológico, me ubico entre los tres primeros siglos de la era cristiana, lo que en historia judía estaría dentro de la época talmúdica (siglos I al VII d.C.); época en que aparece y se va oficializando una nueva forma de vivir la religión de Israel: el Judaismo Rabinico, ${ }^{2}$ el mismo que instaurará un nuevo sistema educativo elemental para la divulgación, formación y posterior redacción de la literatura rabínica (Mishná y Talmud), literatura que se unirá y comentará a la ya existente Torá o Ley oral.

Este nuevo sistema educativo elemental —que inclusive tiene sus orígenes en el primer siglo antes de Cristo- revolucionará la forma de

2 Al dejar de existir el Templo de Jerusalén (70 d. C.), el sacerdocio desaparecerá para dar paso al maestro de la comunidad o Rabino, con quien se reunirán en torno a la Sinagoga. 
enseñanza que hasta entonces se daba, la cual descansaba en los maestros ambulantes y la enseñanza sacerdotal, ${ }^{3}$ por ello, se hizo más laica, comunitaria; obligatoria en la niñez (Bet ha-Sefer), participativa en la adolescencia (Bet haTalmud) y especializada en la adultez (Bet ha-Midras).

No es mi intención abarcar en su totalidad el tema de la educación judía talmúdica rabínica en el presente artículo, pero sí presentar una lectura amena, comprensible y motivadora al lector común, quien muchas veces no está familiarizado con términos técnicos y teológicos. En cambio, para el lector especializado en las ciencias religiosas, mi interés es que descubra el mundo educativo en que le tocó desarrollarse al naciente cristianismo. Así se logrará «fomentar y recomendar el mutuo conocimiento y aprecio [...] que se consigue sobre todo por medio de los estudios bíblicos y teológicos y con el diálogo fraterno» (Nostra Eatate N.o 4).

\section{Cuadro 1: División histórica del Judaísmo}

\begin{tabular}{|c|c|c|}
\hline \multirow{6}{*}{ JUDAÍSMO } & \multirow{2}{*}{$\begin{array}{c}\text { Judaísmo } \\
\text { del } \\
\text { Segundo Templo } \\
\text { (538 a.C. }-70 \text { d.C.) }\end{array}$} & Judaísmo Persa \\
\hline & & $\begin{array}{c}\text { Judaísmo Helenístico- } \\
\text { Romano }\end{array}$ \\
\hline & \multirow{4}{*}{$\begin{array}{c}\text { Judaísmo } \\
\text { Rabínico } \\
\text { (70 d.C. }- \text { Actualidad) }\end{array}$} & Talmúdico \\
\hline & & Medieval-Moderno \\
\hline & & Ilustración \\
\hline & & Contemporáneo \\
\hline
\end{tabular}

3 Para conocer cómo era la educación judía antes de la era cristiana invito al lector a consultar Instituciones del Antiguo Testamento, de R. de Vaux (Barcelona: Herder, 1964, pp. 86-89, 458-460 y 504). 
LOS MAESTROS REFORMISTAS

Si se trata de lo perdido del padre y lo perdido del maestro, tiene precedencia lo perdido del maestro; pues el padre se limita a traernos a este mundo, pero el maestro, que enseña la sabiduría, da la vida del mundo venidero

Misnà Babà mesià [puerta media] 2,11.

El primer cambio hacia una educación elemental será realizado por Simeón Ben Shetah (120 - 40 a.C.). Este miembro de la comunidad de los fariseos llegó a obtener la presidencia del Sanedrín entre los años 103 al 76 a. C. Desde este cargo, hizo que en dicha institución sea mayoritaria y decisiva la presencia farisea frente a sus opositores los saduceos. Y por su condición de hermano de la reina Alejandra Salomé de Judea, fue regente como su sucesor entre los años 76 al 67 a.C. Por tales motivos será considerado un Nasì, esto significa 'representante religioso y político de la comunidad', reconocido así por las autoridades extranjeras

Sea por su formación religiosa farisea, por su trabajo legalista o por su experiencia política, Ben Shetah logró mantenerse como líder de referencia para la comunidad judía de Palestina, y frente a la influencia helenística que se daba en su tiempo, la cual arriesgaba la existencia del judaísmo - especialmente en lo que concierne a la cultura y religión-, no encontró mejor manera de contrarrestarla mediante la fundación de escuelas elementales para los niños en Jerusalén. Esto significaba que la educación pasaba a formar parte de las preocupaciones y tareas de toda la comunidad y no solamente del padre de familia, quien después de dar los contenidos básicos de enseñanza, libremente enviaba al hijo a seguir reforzando su tradición en dichas escuelas. ${ }^{4}$

4 Algunos autores proponen que las escuelas surgen para educar especialmente a los niños huérfanos. 
Pero es en el siglo I d. C. que las escuelas elementales se multiplicarán en todos los poblados de Palestina que tenían sinagogas. En consecuencia, se ormó una gran red educativa, obra que fue promovida por Josué ben Guemala, quien llegó a ocupar el cargo de Sumo Sacerdote entre los años 63 hasta el 65 d.C.

El Talmud de Babilonia ha dedicado varias líneas de agradecimiento a Josué ben Guemala, así por ejemplo se dice que si no hubiera sido por él, se habría olvidado la Torá en Israel. Para el año 64 d.C., ${ }^{5}$ decretó que todas las comunidades nombraran a un Melamdei Tinokot o 'responsable de escuela', que los gastos de dicha institución elemental —especie de jardines infantiles - fueran sufragados por la propia comunidad y que los niños asistieran a ellas a partir de los seis años de edad.

Por último, el Talmud hace mención a un tercer personaje que sobresale especialmente por sus recomendaciones en lo que concierne a la labor educativa. Samuel Ben Shilat propuso que ningún maestro debe dirigir una clase conformada por más de veinticinco niños, y en el caso de que tuviera apoyo de un asistente, el grupo no sería mayor de cuarenta infantes. Por otro lado, sostuvo que el maestro debe demostrar firmeza, pero también afectivividad con su alumno, el cual no debe ser menor de seis años de edad (institucionalizó la edad), y abstenerse de dar castigos corporales si no eran necesarios. ${ }^{6}$

5 Seis años antes de la destrucción del Templo y de la ciudad de Jerusalén (70 d. C.).

${ }^{6}$ Si tenía que recurrir a los azotes, debía usar una correa pequeña y no un palo. 


\section{La EDUCACIÓN BásICA (Bet ha-Sefer)}

Tú en cambio persevera en lo que aprendiste [...] y que desde niño conoces las Sagradas Letras, que pueden darte la sabiduría que lleva a la salvación...

La enseñanza elemental se iniciaba en el Bet ha-Sefer o 'casa del libro', nombre dado debido a que en dicha institución el estudio se centraba en la Torá o Ley escrita, lo que nosotros conocemos también como el Pentateuco o los «cinco rollos», 7 y que según la tradición fueron escritos por Moisés.

Unido a la Torá, se enseñaba otras materias como la Aritmética y la medición del tiempo (Cronología), indispensables para ubicar las fechas de las fiestas anuales. Esto porque «desde su más tierna infancia, el judío aprende y experimenta lo que significa subir y bajar. Cada año, para las fiestas de peregrinación, sube a Jerusalén con sus padres y su familia» (Vidal 2005: 249).

Con respecto al ambiente de estudio, el Bet ha-Sefer se ubicaba «normalmente en dependencias que se encontraban junto a la sala de reunión de la sinagoga. En comunidades más pobres, en cambio, la enseñanza escolar se realizaba en la misma sala de reunión» (Bravo 2006:29).

En dicha institución, se educaban a los niños a partir de los seis años de edad. "Las niñas no estaban obligadas y las opiniones estaban divididas sobre la conveniencia de hacerlas asistir; hay quien recomienda que se les enseñe las nociones de la Torá, pero otros opinan "el que enseña a su hija la Torá, la lleva por el mal camino”» (Rodríguez 2002b: 481).

La finalidad de la enseñanza en este nivel era que el niño dominara la Torá, tanto en su lectura (recitación) como en su dominio (memorización) para aplicarlo en toda la vida. Los estudios se iniciaban con el principal libro ${ }^{8}$ de la Torá, el Levítico.

7 A saber, Génesis, Éxodo, Levítico, Números y Deuteronomio.

8 El término original sería rollo, omitido por motivos de comprensión. 


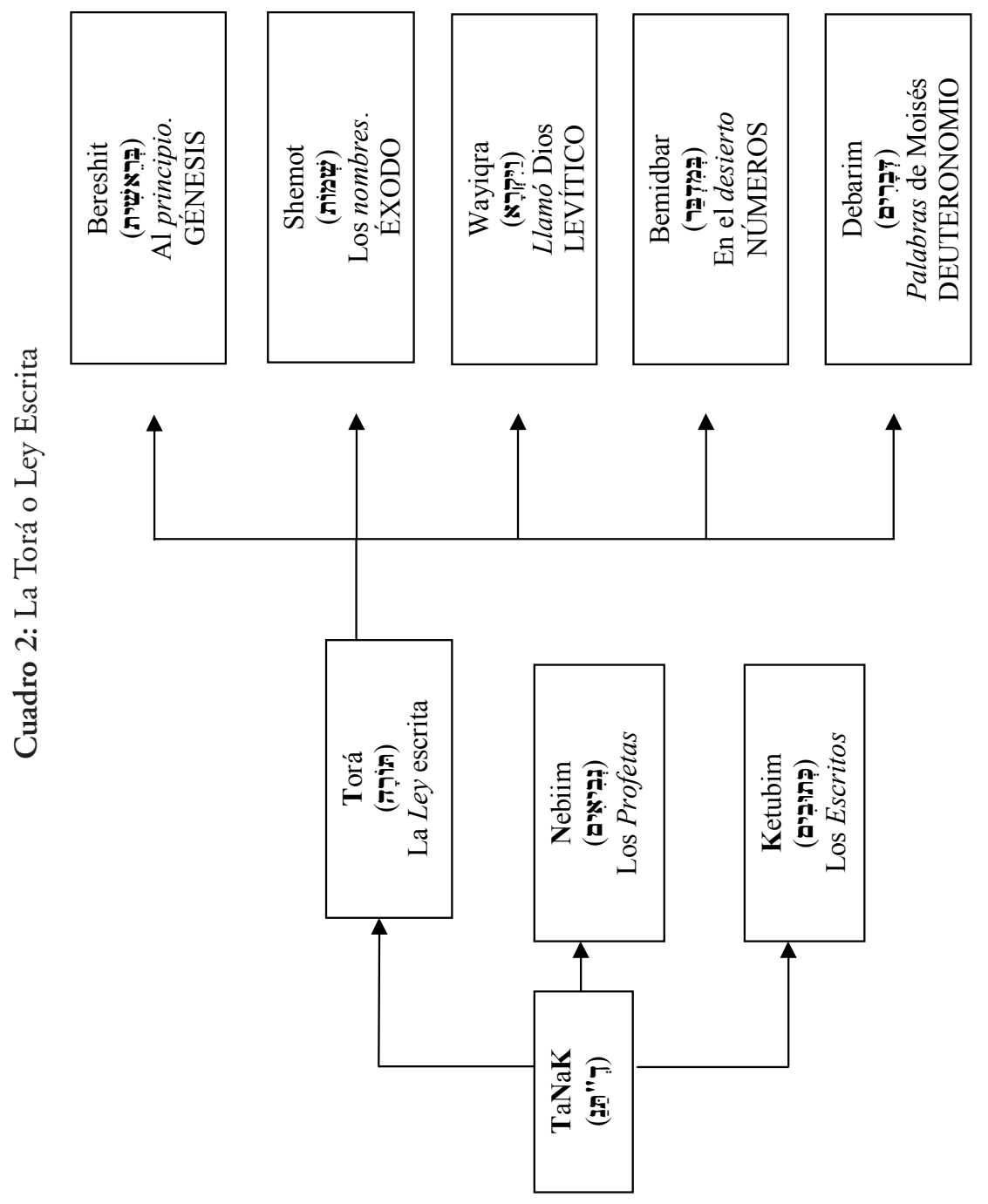


Tres son las razones principales por las cuales el estudio comenzaba por el libro del Levítico. En primer lugar, era indispensable que desde muy temprana edad el niño conociera las leyes del pueblo (Lev. 17-26). En segundo lugar, considerarse como miembro del pueblo "santo" elegido por Dios (Lev. 19-20). Por último, porque existe la creencia —hasta la actualidad - que en tiempos remotos los sacerdotes «iniciaban» a sus hijos a partir del mencionado libro.

El encargado de cumplir la función de maestro era el Sofer, quien diariamente enseñaba a los niños partes o fragmentos de la Torá, ayudado o asistido por el Hazzan. Ambos personajes no habían surgido con la reforma educativa, sino que formaban parte de los funcionarios o servidores de las Sinagogas. Así tenemos que el Sofer era el secretario, a quien correspondía escribir o copiar en rollos sagrados, los textos de la Torá; mientras que el segundo, se encargaba de cuidar y conservar dichos rollos sagrados.

La sesión de aprendizaje se iniciaba cuando los niños «se sentaban en el suelo a los pies del maestro» (Armstrong 1989: 26). A continuación, se daba la instrucción oral, por parte del Sofer, quien recitaba ciertas partes de la Torá, para ello podía hacer uso de pequeñas tablillas de cera para escribir, con un estilete, las letras iniciales.

La referencia o cita de ciertas partes de la Torá era muy diferente a la forma como se hace ahora. Es conocida la división de la Biblia en capítulos y versículos es una obra realizada en la Edad Media y Moderna. ${ }^{9} \mathrm{Al}$ respecto el padre Eduardo Arens explica que:

Originalmente, ninguno de los escritos llevaba un título como el que tiene ahora, [...] era solamente el texto. [...] Marcos 12,26 nos proporciona un ejemplo de la manera en que citaban los textos bíblicos: «No han leído en el libro de Moisés (=Éxodo), en lo de la zarza (=Capitulo tercero), cómo le dijo Dios diciendo: ... (= sigue una cita textual de Ex. 3.6)». (1990: 28)

9 En 1214, el inglés Esteban Langton divide la Biblia en capítulos y en 1555 es Robert Eistenne quien hace la división en versículos. 
A continuación, se daba el aprendizaje por parte de los niños, mediante la repetición y la memorización. La repetición comprendía la recitación de las letras iniciales grabadas en las tablillas, posteriormente se pasaba a la lectura de las escrituras en pequeños rollos denominados Megillah, para luego finalizar en la lectura propia de la Torá. Era en este momento que se iniciaba la memorización de la escritura oficial a partir de la lectura en voz alta y la Saná o «repetición continua», «que habitualmente estaba acompañada de una determinada entonación que la convertía en una especie de canturreo» (Bravo 2006: 36).

Cabe señalar que en ciertos sectores del mundo judío actual, existe una práctica que tiene sus orígenes en el Bet ha-Sefer de esos tiempos y que podemos considerarlo no solamente como una motivación, sino también como una estrategia de aprendizaje, a saber:

En Europa Oriental existe la costumbre de dar a los niños, antes de empezar, las 22 letras del alefato bañadas en miel para que las chupen. Se trata de empezar con una buena impresión, dejar un buen recuerdo y hacer experimentar de forma concreta que las palabras de la Torá son dulces como la miel. (Rodríguez 2002b: 481)

Finalmente, son diversas las opiniones en referencia al uso de la escritura — sea tanto en la enseñanza básica, media, como en la especializada-, por ejemplo, Arturo Bravo, considera que:

La escritura era una habilidad profesional que se adquiría en forma separada. [...] y que se diga que era algo propio de los sabios indica que no pertenecía a los contenidos enseñados en la escuela elemental. [...] la no enseñanza de la escritura como una habilidad completa en la escuela básica. Se puede haber aprendido rudimentos de escritura [...]. (2006: 33)

Basándose en Gunter Stemberger, el filólogo y biblista Antonio Rodríguez Carmona considera que el uso no cotidiano y formal de la 
escritura en los estudios respondía al respeto que se debía de guardar a la Torá, en cualquiera de sus dos naturalezas:

Muchos maestros y estudiantes usaban la escritura como ayuda para conservar las enseñanzas, pero no podían usarla especialmente en público de acuerdo con la naturaleza de la Torá escrita y oral que exigía que cada una emplease de acuerdo con su carácter, la Torá escrita leída y la Torà oral de memoria. (2002b:484)

\section{La Educación Media (Bet ha-Talmud)}

... al cabo de tres días, le encontraron en el templo sentado en medio de los maestros, escuchándoles y preguntándoles...

El Bet ha-Talmud o 'casa del estudio o de la doctrina, era el segundo momento o nivel dentro de la enseñanza elemental, en la que participaban los jóvenes entre los diez y quince años aproximadamente.

En el Bet ha-Talmud, el Mashnèh o 'maestro', tenía la misión de enseñar y transmitir a su Talmid ${ }^{10}$ o 'discípulo', la observancia de la Mishná o Ley oral.

La Mishná o Ley oral es el complemento de la Torá o Ley escrita. Según la tradición rabínica ortodoxa, ambas tienen origen divino y fueron recibidas y transmitidas (oralmente) desde Moisés y para todas las generaciones posteriores.

10 Término que será utilizado con mayor frecuencia en los estudios especializados o Bet ha-Midras. 


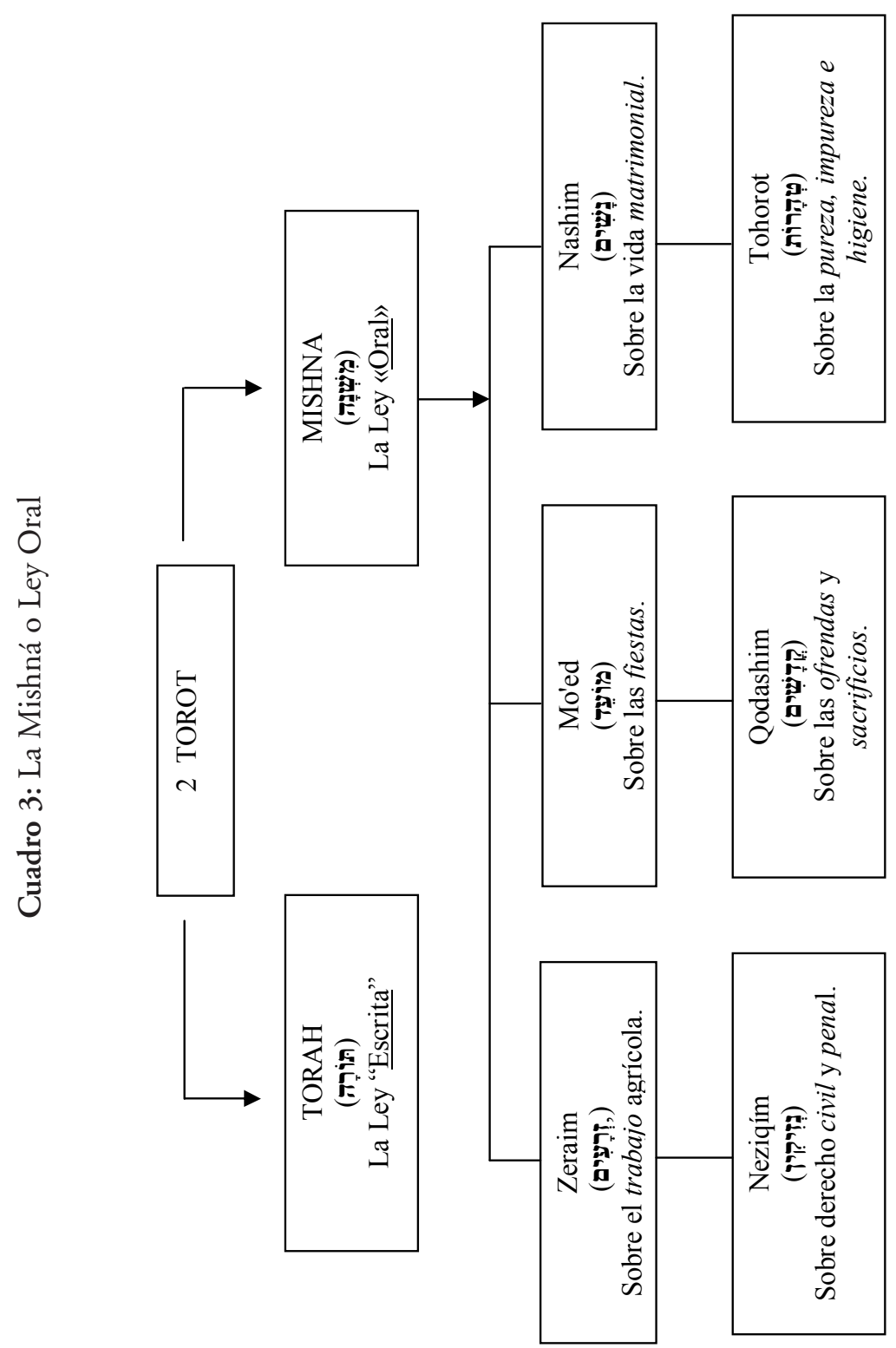


Se considera históricamente que fue a partir del primer siglo de la era cristiana que los círculos de estudios fariseos presentaron la Mishná al pueblo judío, como una lista suelta de tratados, normas u observancias que fueron heredadas de sus padres y, por lo tanto, no fueron puestas por escrito en la Torá, Inclusive «la Toràh oral aparece como la interpretación primera, indispensable para la Toràh escrita» (Poupard 1997: 997).

Es así que la Mishná terminará siendo el fruto de las diversas leyes tradicionales que nacieron en el seno de las escuelas rabínicas fariseas, siendo posteriormente $-\mathrm{y}$ por diversas razones- recopilados y puestos por escrito en hebreo, por hombres intelectuales y religiosos denominados los tannaitas ('repetidores o instructores'), entre el año 10 d.C. hasta el 220 d.C. aproximadamente.

Teniendo como base el dominio de la Torá, el Mashnèh «explicaba el tema o la norma a tratar y alentaba a los estudiantes a participar haciendo preguntas y tratando de que ellos la explicasen» (Bravo 2006:34).

El uso de la repetición y de la memorización seguirán formando parte de los medios de aprendizaje en esta etapa, pero unidos a ellos se encuentra la actividad del Talmid de trabajar en compañía de otro (grupos de dos), con el fin de escrutar la Torá y la Mishná como también reforzar los nuevos aprendizajes a partir de discusiones entre ellos mismos o con el Mashnèh.

Además, se llegará a formalizar en el Bet ha-Talmud — y continuará en las escuelas rabínicas - la costumbre de terminar la sesión de estudios, con la recitación de la oración aramea del Qaddish o 'Santo'. Mediante el cual se santificaba el nombre de Dios, como agradecimiento no solamente de haber heredado la Ley, sino del «don» de poder escrutarlo, como también agradecer — por parte de los alumnos— por el maestro que orientaba la enseñanza. ${ }^{11} \mathrm{Al}$ respecto Ángel Ciriza explica que:

El Qaddish estuvo relacionado en origen con los maestros o predicadores. Cuando el maestro terminaba la lección y el predicador el sermón, añadía una oración de contenido mesiánico

11 Era utilizada también en la liturgia sinanogal y en los ritos fúnebres. 
[...] sus palabras se inspiran en el texto de Ezequiel 38,23. [...] A este rezo de despedida hecho por el maestro, respondía el alumnado o la comunidad con la eulogía «Sea su nombre grande, o también sea su nombre bendito por toda la eternidad». [...] El Qaddish tuvo originalmente relación con la escuela, y la ha mantenido a través del tiempo, pues ha sido propio de los alumnos recitar el Qaddish, alabando a Dios y rogando por sus maestros. El Qaddish que se llama de «nuestros maestros» se reza al terminar un tratado del Mishná o Talmud o algún capitulo leído por el maestro. (2004: 98-99)

De los seis párrafos que comprenden la oración del Qaddish, los cuatro últimos son reservados a los maestros y/o rabinos que unidos a sus discípulos, la recitaban. Según Marie Vidal (2005:182), estos cuatro párrafos son:

«Sobre Israel y sobre los Rabinos y sobre sus discípulos y sobre todos los discípulos de sus discípulos y sobre todos los que se ocupan de su Torah, en este lugar y en todo lugar, para nosotros y para ellos haya gran paz, gracia, amor larga vida y alimento, abundancia y liberación, ante el Dueño Soberano que está en el cielo y en la tierra.

Decid: ¡Amen!»

«Venga gran paz de los cielos, vida, plenitud, salvación, Consuelo, liberación, curación, redención, Indulgencia y perdón, abundancia, rescate, sobre Nosotros y sobre todo el pueblo de Israel Decid: ¡Amen!»

«Recibe con Ternura y Complacencia nuestra oración. Sean recibidas la oración y la petición de todo Israel ante su Padre que está en el cielo y en la tierra, Decid: ¡Amen!» 
«El que da la Paz en las alturas,

Él, en su ternura,

Nos dé la Paz a nosotros y a todo Israel,

Decid: ¡Amen!»

La estancia del alumno en el Bet ha-Talmud quedaba marcada aún más, cuando y en paralelo a sus estudios, celebraba el rito del Bar Mitsvah, ${ }^{12}$ término que significa 'hijo del mandamiento u obligado al mandamiento'. Según Mariel Vidal se celebraba a los «doce años cumplidos» (2005: 250). Otros autores como Johann Maier (1996: 61) y Antonio Rodríguez (2002b: 680) lo ubican al cumplir exactamente los trece años de edad. Dicho ritual se celebraba en la sinagoga, el sábado siguiente de haber cumplido la edad respectiva, en donde se recitaba por primera vez en público la Torá. Podríamos considerarlo un rito de transición y de socialización, pues el niño pasaba a ser un adulto cumplidor de las obligaciones religiosas. ${ }^{13}$ Esto quedaba posteriormente reflejado en su participación activa dentro de la liturgia sinagogal.

\section{LA EDUCACIÓN ESPECIALIZAdA (Bet ha-Midras)}

Los sabios de la escuela de Hilel eran afables y modestos. No solo estudiaban sus propias tradiciones, sino también las tradiciones de la escuela de Shamay. Si, incluso transmitian las enseñanzas de la escuela de Shamay antes de trasmitir las suyas propias.

De b. eburìn [fusiones] 13b.

Al finalizar su formación elemental, el joven judío mantenía y reforzaba todo lo aprendido anteriormente, mediante su participación —unido a su comunidad - del culto diario y sabático en la sinagoga y en las principales

12 El mismo rito lo celebran las niñas (Bat Mitsvah) desde inicios del siglo XIX y solamente dentro del Judaísmo Reformado o Liberal.

13 Es en este contexto que se debe ubicar la escena de «Jesús entre los doctores» (Lc 2, 41-47). 
fiestas celebradas en el aún existente Templo de Jerusalén o después de su destrucción. Pero si deseaba seguir una educación especializada y superior en el conocimiento y aplicación de la Torá, tenía que buscar, elegir y ponerse bajo la tutela de un Rabí o 'mi maestro, maestro mío'.

Conviene aclarar que en el primer siglo de la era cristiana, el título de Rabi era de connotación honorífica, mientras que para los siglos posteriores, identificaría un grado final de conocimiento teológico. Así lo confirma Francisco Varo cuando señala que

En tiempo de Jesús la palabra rabí aún no tenía la significación especifica que adquiriría en el siglo II y que llegó a constituir algo así como un grado académico y de responsabilidad en la enseñanza de la comunidad judía, [...] en los años en que vivió Jesús, esa denominación era sólo un título con el que se honraba en la conversación a personas sobresalientes por su sabiduría y prudencia. (2007:140)

Este tercer y último nivel de enseñanza era conocido como Bet ha-Midras o "Casa de la Instrucción o Interpretación», ${ }^{14}$ lugar donde participaba cualquier joven adulto que deseaba especializarse como escriba (teólogo) y/o rabí (jurista). Este, al finalizar su formación, se ponía al servicio de su comunidad. Especialmente procedía de alguna familia distinguida o simplemente porque era parte de la tradición o herencia familiar.

Con respecto a la edad en que se iniciaba en dichos estudios, las referencias son variadas. Arturo Bravo afirma que se daba «a la edad de doce o trece años» (2006:38); María del Pilar Quicios, «después de los quince años» (2002: 281), y Antonio Rodríguez, «a la edad de diez años» (2002b: 482). Por motivos didácticos seguiré la referencia del Pirket Avot que indica a partir de los quince años.

El Bet ha-Midras era en sí el propio círculo de Talmidim o 'discípulos' que se formaban alrededor de un rabí, quien se caracterizaba

14 Es la única denominación que aparece en la Biblia (Eclesiástico 51,23). 
por tener un tipo de interpretación de la Torá y de la Mishná — según el movimiento religioso al que pertenecía - muy diferente a otros rabinos. Era el joven interesado quien elegía al rabí para su formación; ${ }^{15}$ para ello tenía en cuenta la reconocida reputación y el vasto conocimiento en la Ley que éste dominaba. Así, por ejemplo, no era extraño que en el primer siglo de la era cristiana, «la juventud judía acudi[era] a Jerusalén de todos los rincones del mundo ${ }^{16}$ para sentarse a los pies de los maestros que allí enseñaban» (Jeremías 2000:316). Esto trajo como consecuencia, que entre los maestros hubiera «rivalidad ${ }^{17}$ y envidias por tener más discípulos que los demás, no permitiendo que un discípulo pasase ${ }^{18}$ a otro maestro» (Rodríguez 2002b: 483).

El modelo de maestro para todos los niveles de enseñanza se encarnaba en la figura del rabí, quien

\begin{abstract}
[...] gozaba de alta posición y estimación sociales; ejercía gran influencia en la comunidad [...]. Según el Talmud, el maestro ideal llevaba una vida religiosa pura y sin mancha, era moderado en comer y beber, amaba su profesión, era paciente, concienzudo, modesto, brillante y alegre [...]. En el primer período, los maestros no recibían paga ni la esperaban, pues consideraban sus deberes docentes como el cumplimiento de una orden o vocación divina $[\ldots]$ tenían derecho a poner fin a sus actividades docentes, pero solo podían ser destituidos por motivos de ignorancia o incompetencia, o por propagar una doctrina falsa. (Marrou 1976: 422-423)
\end{abstract}

15 Caso contrario lo encontramos en Jesús, quien escoge a sus discípulos (Mt 4, 18-22; Mc 3,13; Lc. 5,27).

16 Saulo, quien proviene de Tarso de Cilicia, llega a Jerusalén para formarse bajo la tutela del maestro Gamaliel (Hech 22,3).

17 Un ejemplo anecdótico lo encontramos en el círculo fariseo del primer siglo, donde sobresalían dos grandes maestros Shammay y Hillel, cada uno con su respectiva escuela.

${ }_{18}$ En este contexto ubicamos la escena de Juan Bautista y sus discípulos que siguen a Jesús (Jn 1,35-39). 
No existía un ambiente de estudio propio. La actividad formativa se podía dar en un local comunal, en una casa particular, después del servicio litúrgico en la sinagoga, pero especialmente, en los espacios en que se desenvolvía diariamente el rabí, ${ }^{19}$ como "en medio del campo, o junto al camino, bajo una higuera o un olivo [...] la plaza del mercado [...] de pueblo en pueblo» (Varo 2007:135).

La formación de los Talmidim podía durar varios años y comprendía dos momentos o etapas importantes. El primero era conocido como «el servicio de los discípulos», que era la convivencia con el maestro y significaba muchas veces romper con el ritmo de vida que se llevaba, pues se buscaba «aprender prácticamente un modo de vida. [...] Esto obligaba al discípulo a vivir en casa del maestro, lo que le exigía dejar la propia casa por bastante tiempo, incluso si estaba casado. A los solteros esta situación los obligaba a retrasar el matrimonio» (Rodríguez 2002b: 482-483).

El siguiente momento correspondía propiamente a la instrucción, para ello el talmid era invitado a sentarse delante de su rabí con el fin de escuchar sus enseñanzas. ${ }^{20}$

19 Encontramos variedad de ejemplos en el ministerio de Jesús (Lc 10,38-39; Mc 1,21-22; Jn 18,1-2).

20 El cúmulo de comentarios y enseñanzas que se desarrollaron en torno a la Ley oral (Mishná), y que fue el trabajo de las importantes escuelas rabínicas será conocido como Talmud. Existiendo dos tipos de Talmud: el de Jerusalén y el de Babilonia, ambos redactados entre los siglos I y $\mathrm{V}$ d.C. 
Cuadro 4: El Talmud (dos versiones)

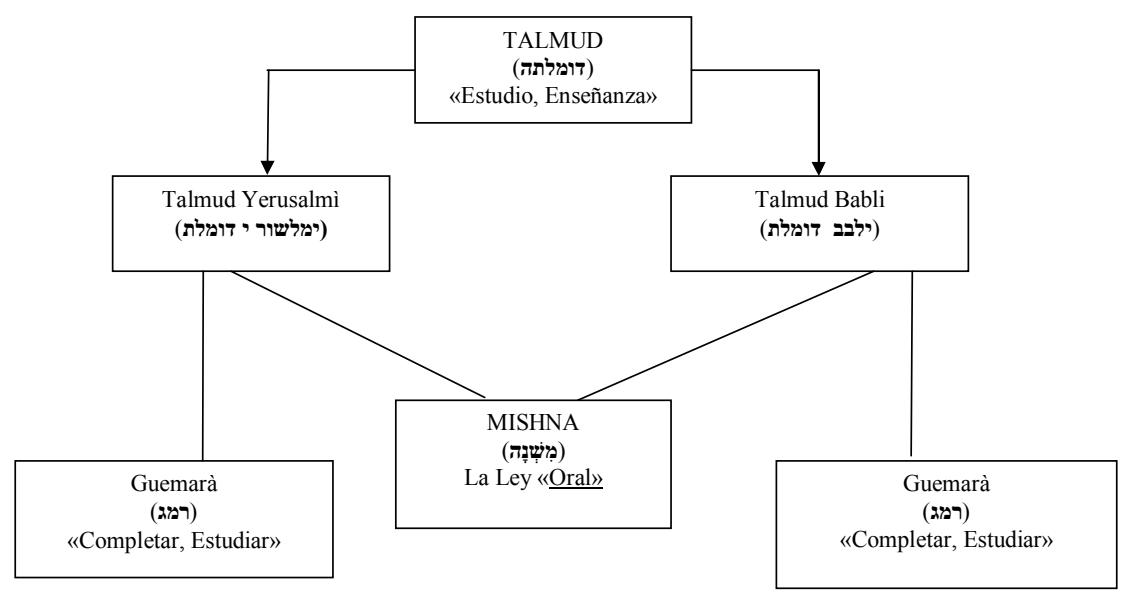

Según Joachim Jeremías, la instrucción finalizaba cuando el talmid «había llegado a dominar toda la materia tradicional y el método [...] hasta el punto de estar capacitado para tomar decisiones personales en las cuestiones de legislación religiosa y de derecho penal» (2000: 308). El mismo autor sostiene que el talmid — ahora candidato a rabi- era considerado un «doctor no ordenado» y que era a partir de los cuarenta años ${ }^{21}$ que podía ser considerado «doctor ordenado»; probablemente, aquí se daba la minnuì ('evaluación o examen'), en donde «el candidato debía dar a conocer sus conocimientos prácticos y teóricos, especialmente si es capaz de decidir libre y automáticamente sobre cuestiones de halaka ${ }^{22}$ y si es capaz de formar discípulos» (Rodríguez 2002b: 484). «A partir de entonces estaba autorizado

21 Edad de la sabiduría (véase Pirke Avout 5,2).

22 Nombre genérico dado a los mandamientos y prohibiciones que se encuentran en la Torá y la Mishná. 
a zanjar por si mismo las cuestiones de legislación religiosa y ritual, a ser juez de procesos criminales y a tomar decisiones en los civiles, bien como miembro de una corte de justicia, bien individualmente. Tenía derecho a ser llamado Rabbi» (Jeremías 2000:308-309).

\section{CONCLUSIONES}

El año 70 d.C. marca un hito importante dentro de la historia de Israel, pues al dejar de existir la ciudad capital, y junto con ella el Templo, la sociedad judía comienza a experimentar una nueva forma de llevar su vida religiosa, educativa y comunitaria. Esta labor será llevada a cabo por el único grupo religioso laico que podrá sobrevivir frente a tal situación: los Fariseos, quienes durante los siguientes decenios fortalecerán la imagen del Rabi. Ante la ausencia del Templo, darán importancia, en primer lugar, a la sinagoga, y en segundo lugar, a la casa común para las celebraciones religiosas, lo que Ariel Segal ${ }^{23}$ denomina el «Templo portátil», en donde la figura del sacerdote quedará suplantada o retomada por el rabi y el padre de familia, contexto histórico concreto en donde se encuentran los orígenes del Judaísmo Ortodoxo actual. ${ }^{24}$

Frente al peligro de poder perder toda su herencia cultural y religiosa, los rabinos fomentaron un sistema educativo en donde toda la enseñanza descansaba en primer lugar en la Torá o Ley escrita. Para ello las instituciones educativas tenían que «transmitir en sentido activo y actualizante, en el que cada generación y cada miembro de la cadena aportan profundización y actualidad»(Rodríguez 2002b: 480). Esto significaba no solamente transmitir la Torá, sino escrutarla y comentarla, lo que trajo como consecuencia la creación, recopilación, ordenación y publicación de la Mishná y el Talmud, grandes obras de la literatura rabínica que, unidas a la

23 Especialista en estudios judaicos del centro cultural de la PUCP.

24 Dentro del judaísmo contemporáneo existen varias corrientes de interpretación, así tenemos el Ortodoxo, Liberal, Reformista, etc. 
Torá, fueron los contenidos elementales en la enseñanza religiosa, heredara hasta nuestros días en las Yeshivas o 'academias religiosas', especialmente en el mundo judío ortodoxo.

Por lo tanto, considero que los principios educacionales dentro del mundo judío rabínico y durante los primeros siglos de la era cristiana siguieron siendo los mismos que acompañaron al pueblo de Israel durante toda su existencia. Estos, según Hayward Armstrong, consideraban que «la educación es un mandato directo de Dios. [...] El prototipo de todos los maestros fue Dios mismo, por lo tanto la enseñanza tenía autoridad. [...] El oficio de enseñar se consideraba sagrado» (1989: 18).

Se buscaba, en primer lugar, mediante la educación transmitir la herencia histórica del pueblo, esto significaba que el niño desde muy pequeño conociera los principales hechos y acontecimientos históricos para poder descubrir en ellos la presencia de Dios. En segundo lugar, se quería formar la conducta ética del futuro hombre piadoso, la cual se alcanzaba por medio de la literatura de la Ley. Por último, se buscaba procurar vivir y enseñar la santidad delante de Dios, especialmente en la observación de los preceptos, fiestas, etcétera, los cuales se iniciaban independientemente en el individuo a partir de la celebración del Bar Mitsvah. 


\section{BIBLIOGRAFÍA}

ARENS S.M., Eduardo

1990 La Biblia sin mitos. Lima: Paulinas.

ARMSTRONG, Hayward

1989 Bases para la educación cristiana. S. 1.: Editorial Mundo Hispano.

AA. VV.

2005 El origen de las grandes religiones. Enciclopedia de Historia Universal. Tomo VII. Lima: Salvat Editores.

BRAVO, Arturo

2006 El estilo pedagógico de Jesús Maestro. Bogota: CELAM.

Brostein, Guillermo

2004 «Algunos conceptos básicos sobre el judaísmo». En Ortmann, Dorothea (coord.). Anuario de Ciencias de la Religión: las religiones en el Perú de hoy. Lima: UNMSM-CONCYTEC, pp. 39-57.

Chico Gonzales, Pedro

2006 Diccionario de Catequesis y Pedagogía Religiosa. 2 volúmenes. Lima: Editorial Bruño.

Ciriza Aguirre, Ángel

2004 «Pirket Avot (Mishná) en el contexto de la tradición de Israel». Catechumenium, revista de Teología, N. ${ }^{\circ} 3$, junio, pp.87-143.

Desclee De Brouwer (Ed.)

1996 Biblia de Jerusalén. Bilbao: Desclée de Brouwer. 
De Tuya O.P., Manuel

1977 Biblia Comentada: Evangelios. Tomo V. Madrid: BAC.

Del Valle, Carlos

2003 La Misnà. Salamanca: Ediciones Sígueme.

Gonzalo Maeso, David

1960 Manual de historia de la Literatura Hebrea. Madrid: Gredos.

JEREMIAS, Joachim

2000 Jerusalén en tiempos de Jesús. Madrid: Ediciones Cristiandad.

MaIER, Johann y SchäFER, Peter

1996 Diccionario del Judaísmo. Navarra: Verbo Divino.

Marrou, Henri

1976 Historia de la educación en la Antigüedad. Buenos Aires: Editorial Universitaria de Buenos Aires.

MeIER, John P.

1998 Un judio Marginal: nueva visión del Jesús histórico. Tomo I. Navarra: Editorial Verbo Divino.

Mertens, Heinrich A.

1989 Manual de la Biblia. Barcelona: Herder.

Pelaez Del Rosal, Jesús

1988 La Sinagoga. Córdoba: Ediciones El Almendro.

POUPARD, Paúl

1997 Diccionario de las religiones. Barcelona: Herder. 
PETUCHOWsKi, Jakob J.

2001 El gran libro de la sabiduría rabinica: historias de los maestros. Santander: Sal Terrae.

Quicios García, María del Pilar

2002 Fundamentos filosóficos de la pedagogía antigua: la educación griega, romana y judeocristiana. Madrid: Ediciones UNED.

Ramos, Marcos A.

2008 Judaismo e Islamismo. Biblioteca de Aula. Tomo 23. Lima: Asociación Editorial Hemisferio.

Rodriguez Carmona, Antonio

2002a "Jesús en y ante el Judaísmo». En Actas del Congreso Internacional de Cristología de la Universidad Católica de San Antonio. España: Cuaderna Editorial, pp. 127-149.

2002b La religión judia: Historia y Teología. Madrid: BAC.

Royston PIKe, Edgar

2001 Diccionario de Religiones. México: Fondo de Cultura Económica.

Soto Canales, Pedro

2007 «Agentes educativos en el Cuzco incaico». Riesgo de Educar, revista de la Facultad de Ciencias de la Educación de la Universidad Católica Sedes Sapientiae, año 2, N.o 3, pp. 74-83.

Tassin, Claude

1987 El Judaísmo: Desde el destierro hasta el tiempo de Jesús. Serie Cuadernos Bíblicos n. ${ }^{\circ} 55$. Navarra: Verbo Divino.

Varo Pineda, Francisco

2007 Rabi Jesús de Nazaret. Madrid: BAC. 
De Vaux, R

1964 Instituciones del Antiguo Testamento. Barcelona: Herder.

VIDAL, Marie

2005 Un judio llamado Jesús: lectura del Evangelio a la luz de la Torah. Baracaldo: Grafite Ediciones. 